\title{
Domiciliary immunisation for preschool child defaulters
}

\author{
A E JONES
}

\begin{abstract}
A selective domiciliary immunisation service has been introduced for preschool children living in the Central Manchester Health District. The service is provided for the children of parents who have given written consent for immunisation but have subsequently failed to bring their children to the clinic or their general practitioner's surgery to start or complete the basic course of immunisation against diphtheria, tetanus, whooping cough, poliomyelitis, and measles. This failure has occurred despite at least two written invitations for each injection and several reminders from the health visitor. Many additional children have been protected by this scheme.
\end{abstract}

\section{Introduction}

An active immunisation policy has been pursued in Manchester for many years. In 1928 the City Council approved a scheme to offer free immunisation against diphtheria "through every possible avenue to the public, but especially in the child welfare clinics, the school medical service, the various children's hospitals and the general practices in the City." Fifteen years later 576 cases and 26 deaths occurred in children under 15 years of age, most if not all of whom had missed the opportunity of immunisation (Annual reports on health of City of Manchester by Medical Officer of Health, 1928 and 1943). Over the years the basic immunisation programme was extended to include whooping cough (1952), poliomyelitis (1956), and measles (1962). Missed opportunity by eligible children continued to be a matter of great concern to the Health Authority.

The health visitor was recognised as the most important single factor in the promotion and implementation of the basic immunisation programme, but other measures were taken to help her.

Environmental Health Department, Town Hall, Manchester M60 2JB

A E JONES, MB, FFCM, medical officer for environmental health

\section{Methods}

Special immunisation campaigns-In an attempt to motivate parents and improve the uptake of immunisation special campaigns were arranged from time to time. Although each campaign showed initial success, no permanent improvement followed. The last unselective campaign in Manchester occurred in 1971, after an outbreak of diphtheria, and 81500 children aged under 16 were immunised or given a booster. ${ }^{.}$Subsequent analysis of the results, however, showed that only $10 \%$ of those immunised at this time were preschool children whose parents had to bring them to the centre as well as give their permission.

Mobile clinic-In 1945 a mobile clinic was provided, using an adapted single decker bus, and an additional full time medical officer with support staff was appointed to operate it. The principal aim was to reach preschool children, especially those who lived at a distance from the nearest clinic. For many years the mobile clinic was responsible for over $25 \%$ of the total basic uptake of immunisation. It acted as a publicity agent as well as providing clinic facilities as near as possible to homes and it operated until 1975, by which time sufficient health centres and additional clinics had been built to bring facilities within walking distance for most families.

A computer controlled immunisation system, introduced in January 1967, resulted in some improvement in the uptake of basic immunisation (table I), but uptake remained much lower than the $88 \%$ reported from West Sussex where computer management was pioneered. ${ }^{2}$

Timing of basic immunisation schedule - In 1969, in accordance with national guidelines, the start of the basic course was postponed from 3 months to 5 months of age, with the second dose at $61 / 2$ months and the third at $11 \frac{1}{2}$ months. Except for 1971, when there was a special campaign, the uptake of primary immunisation in preschool children remained well below $70 \%$ until 1977 (table I). Failure to attend for the third dose greatly reduced the number of completed courses. At $11 \frac{1 / 2}{2}$ months parental motivation had waned or mothers had returned to work and were unavailable to keep appointments. In 1976 a local immunisation advisory committee discussed the problem and recommended that the basic course of immunisation shouid start at 3 months of age and the interval between doses be reduced so that the course might be completed at 6-7 months while parental motivation was at its highest.

All these measures played a part in improving the uptake of basic immunisation, and between 1975 and 1981 the uptake of diphtheria, tetanus, and polio immunisation in Manchester (North, Central, and South Manchester Health Authorities) increased from $62 \%$ to $78 \%$ (table I). Part of this increase would have resulted from the change in guidelines of the Department of Health and Social Security in 1978. Until 1978 a child was not 
included in the number of "completed courses" if the interval between doses exceeded what was recommended. Fortunately, national guidelines (MO(78)15) advised that previous doses are not invalidated if a course has been interrupted and the recommended interval exceeded.

A study of the computer returns from the Central Manchester Health Authority in 1981, however, showed that many children whose parents had given valid consent had received no immunisation or only an incomplete course. The health visitors were convinced that many of these defaulters would not be brought to the clinic despite all their efforts. It was agreed, therefore, to undertake a pilot study to assess the feasibility of a domiciliary service and its acceptability to the parents. These proposals were approved by the local medical committee, and in 1981 the Director of Nursing Services (Community) appointed one state enrolled nurse to spend eight sessions each week on the project. Within the first two months the service was shown clearly to be feasible, acceptable to the parents, and very effective.

Domiciliary service-Referrals to the domiciliary service were received from health visitors and included only infants whose parents had given valid consent for immunisation and whom the health visitor was convinced would not be brought to the clinic or surgery for immunisation. Each week the immunisation nurse visited all health centres and clinics to receive referrals from individual health visitors plus any information about the families that might be helpful. She visited each family at home to offer the domiciliary service and, if this was accepted, discussed mutually convenient dates and times for immunisation. An itinerary was planned for an average of two sessions a week, depending on the availability of a doctor. The equipment consisted of a bag containing a stethoscope, vaccines, adrenalin, disposable syringes, needles, swabs, and dressings, with a container for used equipment. A doctor travelled with the nurse, who used her own car on the immunisation round. An unscheduled immunisation form was completed for the first injection given at home, using the code number allocated to the domiciliary service. When the unscheduled forms were received at the community offices each child's previous treatment centre was changed to "domiciliary." If a further injection was needed to complete the course the computer sent the invitation postcard directly to the nurse at her office. She filled in the date and time and posted or delivered the card to fit in with an arranged domiciliary session. Every procedure for immunisation undertaken in the home was notified to the referring health visitor.

\section{Results}

Table I shows the uptake of primary immunisations in Manchester from 1961 to 1983 and the response to local initiative. The very low levels of uptake in 1968-75 also reflect Manchester's strict observance of the interval between doses as laid down in the DHSS guidelines. Table II gives details of the performance of the domiciliary immunisation service. In 1982, 71 children and, in 1983, 46 children started a course of primary immunisation, but most children referred to the domiciliary service needed only a second or third dose, or both, to complete a course started elsewhere. In 1983 considerable progress was made in promoting immunisation to measles; 52 children were protected compared with 16 in 1982.

In each of the years 1982 and 1983 about 150 children received one or more

TABLE I-Completed basic courses of immunisation against diphtheria, tetanus, and poliomyelitis for children in Manchester, 1961-83*

\begin{tabular}{|c|c|c|c|}
\hline $\begin{array}{l}\text { Year of } \\
\text { birth }\end{array}$ & $\begin{array}{l}\text { Immunised by } \\
\text { the end of: }\end{array}$ & $\begin{array}{l}\text { Proportion (\%) of } \\
\text { live births } \\
\text { completing basic } \\
\text { course }\end{array}$ & $\begin{array}{l}\text { Factors influencing } \\
\text { proportion immunised }\end{array}$ \\
\hline 1959 & 1961 & 62 & \\
\hline 1960 & 1962 & $\begin{array}{l}02 \\
63\end{array}$ & \\
\hline 1961 & 1963 & 61 & \\
\hline 1962 & 1964 & 59 & \\
\hline 1963 & 1965 & 56 & \\
\hline 1964 & 1966 & 57 & \\
\hline 1965 & 1967 & 58 & Computer managed system introduced \\
\hline 1966 & 1968 & 57 & \\
\hline 1967 & 1969 & 29 & $\begin{array}{l}\text { First dose postponed to } 5 \text { months and } \\
\text { longer intervals between doses }\end{array}$ \\
\hline 1968 & 1970 & 63 & \\
\hline 1969 & 1971 & 72 & Special immunisation campaign \\
\hline 1970 & 1972 & 65 & \\
\hline 1971 & 1973 & 64 & \\
\hline 1973 & 1975 & 62 & \\
\hline 1974 & 1976 & 67 & \\
\hline 1975 & 1977 & 72 & $\begin{array}{l}\text { First dose at } 3 \text { months and reduced } \\
\text { intervals between doses; change in } \\
\text { DHSS guidelincs }\end{array}$ \\
\hline 1976 & 1978 & 71 & \\
\hline 1977 & 1979 & 75 & \\
\hline 1978 & 1980 & 78 & \\
\hline 1979 & 1981 & 78 & \\
\hline 1980 & 1982 & 81 & Domiciliary service introduced \\
\hline 1981 & 1983 & 80 & \\
\hline
\end{tabular}

* Data for 1961-82 refer to the City of Manchester; those for 1983 are from Central Manchester Health Authority alone.
TABLE II-Domiciliary immunisation in 1982 and 1983

\begin{tabular}{|c|c|c|c|c|c|c|c|c|c|c|c|c|c|c|}
\hline \multirow{2}{*}{ Year } & \multirow{2}{*}{$\begin{array}{c}\text { No of } \\
\text { children }\end{array}$} & \multicolumn{3}{|c|}{$\begin{array}{l}\text { DT VacAds } \\
\text { dose: }\end{array}$} & \multicolumn{3}{|c|}{$\begin{array}{l}\text { DTPer VacAds } \\
\text { dose: }\end{array}$} & \multicolumn{3}{|c|}{$\begin{array}{l}\text { Oral polio } \\
\text { dose: }\end{array}$} & \multicolumn{4}{|c|}{$\begin{array}{l}\text { Measles pertussis } \\
\text { dose: }\end{array}$} \\
\hline & & 1 & 2 & 3 & 1 & 2 & 3 & 1 & 2 & 3 & & 1 & 2 & 3 \\
\hline $\begin{array}{l}1982 \\
1983\end{array}$ & $\begin{array}{l}149 \\
156\end{array}$ & $\begin{array}{l}60 \\
35\end{array}$ & $\begin{array}{l}61 \\
53\end{array}$ & $\begin{array}{l}53 \\
64\end{array}$ & $\begin{array}{l}11 \\
11\end{array}$ & $\begin{array}{l}19 \\
18\end{array}$ & $\begin{array}{l}23 \\
19\end{array}$ & $\begin{array}{l}74 \\
46\end{array}$ & $\begin{array}{l}83 \\
73\end{array}$ & $\begin{array}{l}79 \\
84\end{array}$ & $\begin{array}{l}16 \\
52\end{array}$ & 2 & 2 & 1 \\
\hline
\end{tabular}

DT VacAds = diphtheria-tetanus vaccine adsorbed;

DTPer VacAds = diphtheria-tetanus-pertussis vaccine adsorbed.

* Number of children successfully contacted at home and receiving one or more doses of vaccine.

doses from the domiciliary service (table II) and it was estimated that this service will be needed for roughly 180 preschool children living in Central Manchester Health Authority District each year-that is, $8 \%$ of births. This estimate does not include children whose parents refused consent or failed to sign consent. The service has been monitored carefully by the nursing administration and the community physician (AEJ) to ensure that it is not misused.

The cost of the domiciliary immunisation service to the Health Authority is roughly $£ 6270$ a year. This is made up of $80 \%$ of the salary of one state enrolled nurse ( $\$ 4344$ ), her travelling expenses ( $£ 926$ ), and the equivalent of 46 sessions for a clinical medical officer ( $£ 1000)$.

\section{Discussion}

The uptake of basic immunisation depends not only on how parents respond to an invitation to sign consent but also on whether they subsequently keep an appointment for immunisation at a mutually agreed centre. The lower the parental cooperation the higher must be the input from the health authority. A high incidence of uptake is more difficult to achieve in preschool children than in school children because, provided valid consent has been given, a health authority may take advantage of the captive population in school. A computer managed immunisation system improves formal communications with parents, but, even if selected and programmed to suit the needs of an individual authority, it unfortunately neither changes parental attitudes nor removes apathy and indifference. For example, during the years 1970-4, and using a similar immunisation schedule and with an equally committed staff, the West Riding Scheme achieved a 95\% uptake of primary immunisation ${ }^{3}$ while the City of Manchester failed to reach $70 \%$ except in 1971 when there was a special campaign. This gives some indication of the challenge facing health workers in large cities, particularly in inner city areas, where, contrary to some informed opinion, ${ }^{4}$ special inducements are needed to achieve a high uptake of immunisations. The published rates of vaccination for Manchester before 1978 are, however, lower than the true uptake of doses because of a strict adherence to the earlier DHSS guidelines.

In 1982 Central Manchester Health Authority was providing community health services for a population of 131900 , somewhat less than one third of the City of Manchester. The number of births was 2128. The district consists of nine electoral wards within the City, all of which are designated by central government as part of the Manchester-Salford Inner City Partnership Area. This inner city district is recognised by central government as an area of multiple deprivation, which is reflected in a negative or sluggish response from many parents to repeated invitations to sign a consent form and bring their child to an agreed location for immunisation. In 1982 only 40 parents (2\%) refused consent for primary immunisation.

The domiciliary service was introduced to protect a vulnerable group of preschool children whose parents had been persuaded to sign consent but, in the opinion of the health visitors, would not otherwise receive immunisation or complete the course, at least until school entry. Most of these children belonged to unskilled manual families and lived in an environment that lowered their resistance to prevalent infections. There was no evidence of child abuse, but the standard of child care was below the average for the district. In most cases there was evidence of parental irresponsibility and serious social problems. None of the mothers had a valid reason for not attending the clinic. Reasons given were, "Don't know," "Always forget," "Can't be bothered." Very few of the mothers 
were employed outside the home and none lived far from a clinic. Most of the children were in one parent families; few were from ethnic minority groups, although often the family consisted of a white mother and several coloured children.

The domiciliary immunisation service is centred on one immunisation nurse who has a commitment to the scheme and has the necessary attributes to be accepted both by the referring health visitor and the defaulting parents. An input is also required from health visitors and medical staff. The skills of the health visitor are used to identify suitable referrals and obtain parental consent. A doctor is needed in the home to assess medical fitness for immunisation and to give the injections, because all the referred children have a very poor clinic attendance record and the standard of child care is below the average for the district. Often an injection has to be deferred on medical grounds.

One particular nurse coordinates the domiciliary immunisation service, but the accompanying doctor is one of a group of interested community health doctors and community physicians. If the duty is shared in this way it cannot be considered to be a burden or a waste of professional time, and it is an effective way of obtaining first hand knowledge of the problems and health needs of the community.

I thank Dr Noel Preston, University of Manchester, for his help and encouragement in preparing this paper.

\section{References}

1 Butterworth A, Abbott JD, Simmons LE, et al. Diphtheria in the Manchester Area, 1967-71. Lancet 1974; ;ii: 1558 .

2 Galloway TMCL. Vaccination and immunization, managed by electronic data processing. Medical Officer 1966;116:58-60.

3 Newman CPStJ. Immunization in childhood and computer scheme participation. Public Health 1983;97:208-13.

4 Anonymous. Failure to vaccinate [Editorial]. Lancet 1983;ii: 1343

(Accepted 31 August 1984

\title{
$\beta$ Blockers after myocardial infarction: have trials changed practice?
}

\author{
N S BABER， D G JULIAN， J A LEWIS， G ROSE
}

\section{Abstract}

A survey of British consultant cardiologists was carried out to elicit their current practices when prescribing long term $\beta$ blockers after myocardial infarction. Sixty $(72 \%)$ of the respondents reported that they used $\beta$ blockers prophylactically even in the absence of any other indications; the details of their stated policies, however, varied considerably.

The favourable evidence of clinical trials in this indication appears to have been assimilated into hospital practice.

\section{Introduction}

Clinical trials have agreed widely that the long term prophylactic use of $\beta$ adrenergic blocking drugs after myocardial infarction reduces mortality, ${ }^{1.5}$ but even though the evidence is probably accepted by most practising physicians, disagreement continues on how it should be translated into clinical practice. Is the reduction in mortality large enough to justify the cost in both human and economic terms? Is $\beta$ blockade only worth while in certain categories of patient? How long is long term? To gain some insight into the effects of this recent research we carried out a simple survey among a sample of British cardiologists to assess their current clinical practice. In addition, we used this opportunity to investigate the feasibility of a clinical trial to establish the effect of withdrawing $\beta$ blockade after one or two years' treatment after myocardial infarction (a "stopping trial").

International Medical Affairs Department, Pharmaceuticals Division, Imperial Chemical Industries PLC, Macclesfield, Cheshire SK10 4TG

N S BABER, MB, MRCP, medical adviser

J A LEWIS, DIPSTAT, FIS, division chief statistician

Department of Cardiology, Freeman Hospital, Newcastle upon Tyne NE7 7DN D G JULIAN, MD, FRCP, professor of cardiology

London School of Hygiene and Tropical Medicine, London WC1E 7HT

G ROSE, FRCP, FFCM, professor of epidemiology

Correspondence to: Dr N S Baber.

\section{Methods}

A random sample of 100 cardiologists was drawn from a list of all British consultant cardiologists. Attempts were made to exclude those not in clinical practice. A questionnaire was sent to each member of the sample. Nonresponders were contacted again, first by letter and then by telephone. Incomplete or unclear forms were also corrected whenever possible after further contact by letter or telephone. Tables I-V show the questions asked. They were intended to be clear and simple and to relate to a limited number of important issues.

\section{Results}

Of the 100 doctors surveyed, six were found not to be practising cardiologists, three stated that they did not have postinfarction patients under their care, four refused to complete the form, and four did not respond in any way. There were thus 83 questionnaires for analysis from the 91 cardiologists supposedly eligible for the survey; 75 were complete.

Tables I-V summarise the responses to the questions. Table I shows that $60(72 \%)$ of the respondents reported that they used $\beta$ blockers prophylactically after myocardial infarction, even when other indications for $\beta$ blockade were absent. Roughly half of these reckoned to treat all patients who did not have a contraindication to $\beta$ blockade. The remaining half reported that they attempted to select patients at high risk. Opinion was about evenly divided on the question of an upper age limit for prophylactic treatment (table II). Those who set an age limit nearly all chose 65 or 70 . Most reckoned to treat patients prophylactically for over a year, and nearly half for more than two years (table III).

TABLE I-Responses to question: "In a patient discharged from hospital following confirmed myocardial infarction, my current practice is to prescribe long term $\beta$ blocking drugs as follows"

\begin{tabular}{lc}
\hline Possible replies & $\begin{array}{c}\text { No (\%) of doctors } \\
\text { choosing reply }\end{array}$ \\
\hline (1) To treat only those patients with other indications for $\beta$ blockade & $23(28)$ \\
$\quad$ (such as hypertension or angina) & $28(34)$ \\
(2) To treat prophylactically all patients who do not have a & contraindication to $\beta$ blockade \\
(3) To treat prophytactically only those patients who are at high risk of & $30(36)$ \\
$\quad$ death or reinfarction (plus those with other indications as in (1) above) & $2(2)$ \\
(4) Other prophylactic use. Please specify & $60(72)$ \\
Total prophylactic use &
\end{tabular}

*"Younger patients who may be at increased risk," and "Policy (3) together with patients withou angina but with a positive post myocardial infarction exercise test. 